\title{
3D Buoyancy-Induced Flow and Entropy Generation of Nanofluid-Filled Open Cavities Having Adiabatic Diamond Shaped Obstacles
}

\author{
Lioua Kolsi $^{1,2}$, Omid Mahian ${ }^{3, *}$, Hakan F. Öztop ${ }^{4,5}$, Walid Aich ${ }^{1,6}$, Mohamed Naceur Borjini ${ }^{2}$, \\ Nidal Abu-Hamdeh ${ }^{5}$ and Habib Ben Aissia ${ }^{2}$ \\ 1 College of Engineering, Mechanical Engineering Department, Haïl University, Haïl City 2240, Saudi Arabia; \\ 1.kolsi@uoh.edu.sa or lioua_enim@yahoo.fr (L.K.); aich_walid@yahoo.fr (W.A.) \\ 2 Unité de Recherche de Métrologie et des Systèmes Energétique, Ecole Nationale d'Ingénieurs, \\ University of Monastir, Monastir City 5000, Tunisia; naceur.borjini@fsm.rnu.tn (M.N.B.); \\ Habib.benaissia@enim.rnu.tn (H.B.A.) \\ 3 Young Researchers and Elite Club, Mashhad Branch, Islamic Azad University, Mashhad 9187147578, Iran \\ 4 Department of Mechanical Engineering, Technology Faculty, Frrat University, Elazig 23119, Turkey; \\ hfoztop1@gmail.com \\ 5 Mechanical Engineering Department, Faculty of Engineering, King Abdulaziz University, P.O. Box 80204, \\ Jeddah 21589, Saudi Arabia; nidal@just.edu.jo \\ 6 Unité de Recherche Matériaux, Énergie et Énergies Renouvelables, Faculté des Sciences de Gafsa, \\ Gafsa 2100, Tunisia \\ * Correspondence: omid.mahian@mshdiau.ac.ir; Tel.: +98-513-843-6545
}

Academic Editor: Kevin H. Knuth

Received: 1 May 2016; Accepted: 15 June 2016; Published: 21 June 2016

\begin{abstract}
A three dimensional computational solution has been obtained to investigate the natural convection and entropy generation of nanofluid-filled open cavities with an adiabatic diamond shaped obstacle. In the model, the finite volume technique was used to solve the governing equations. Based on the configuration, the cavity is heated from the left vertical wall and the diamond shape was chosen as adiabatic. Effects of nanoparticle volume fraction, Rayleigh number $\left(10^{3} \leqslant \mathrm{Ra} \leqslant 10^{6}\right)$ and width of diamond shape were studied as governing parameters. It was found that the geometry of the partition is a control parameter for heat and fluid flow inside the open enclosure.
\end{abstract}

Keywords: numerical; three dimensional; open cavity; nanofluids; entropy generation

\section{Introduction}

The work on open systems is vital in the design of electronic cooling, heating and cooling of building, ventilation, food industry and solar applications. Bilgen and Öztop [1] solved via a finite volume method the two-dimensional governing equations of 2D natural convection in partially open inclined cavities. Prakash et al. [2] studied different heat transfer areas using Fluent. A buoyancy-induced flow loss is observed to increase with increasing opening ratio. This increment in buoyancy-induced flow loss for different inclination angles is found to range between $30 \%-80 \%$ when the opening ratio is increased from $1 / 4$ to $1 / 2$ for all closed space shapes. Zamora and Kaiser [3] solved the convective flows in cubical open cavities. They investigated the influence of an internal wall (adiabatic or isothermal) as well as the slope of an external heated wall on flow structure and heat transfer.

The number of studies on buoyancy-induced flow in nanofluid-filled open cavities, has increased recently. In this context, buoyancy-induced flow of a SWCNT-nanofluid (single-walled carbon nanotube nanofluids) in an open enclosure was studied by Jafari et al. using a lattice Boltzmann 
simulation [4]. It is mainly a square closed space heated with an isothermal vertical wall. They observed that the aspect ratio of the closed space plays an important role in buoyancy-induced flow and an increase of this parameter leads to heat transfer reduction in the target problem. Sheremet et al. [5] applied the curvilinear boundary conditions on a nanofluid-filled wavy walled closed space and they found that both waviness and nanoparticle volume rate are effective parameters in buoyancy-induced flow and heat transfer.

Using the lattice Boltzmann approach, Kefayati [6] studied the entropy generation due to laminar buoyancy induced flow in a square closed space filled with non-Newtonian nanofluid. He observed that total entropy production rises with the Ra number and the increase in volume fraction enhances entropy generation due to heat and fluid flow in different power-law indexes. Later, Kefayati [7] employed the lattice Boltzmann method to investigate the free convection in an open cavity in the presence of MHD flow using alumina/water nanofluid. Mejri and Mahmoudi [8] applied a magnetic field on buoyancy-induced flow heat transfer in a nanofluid-filled open enclosure.

Öztop and Salem [9] performed a review to present on entropy-related work with energy systems including buoyancy-induced flow. There are few works on three-dimensional analysis of entropy generation. Öztop et al. [10] numerically studied the three-dimensional heat transfer and entropy generation due to combined buoyancy and thermocapillary convection in a cubic cavity. Their results elucidated that at low Rayleigh numbers, the Marangoni number influence on the total entropy generation rises. Entropy generation for buoyancy-induced flow in a partitioned closed space, with adiabatic horizontal and isothermally cooled vertical walls, is studied numerically by Famouri and Hooman [11]. They presented the effects of fluid friction on entropy production is weak and the heat transfer irreversibility increases almost linearly with the $N u$ number and the temperature difference.

Mehrez et al. [12] exploited the finite-volume method to study the MHD flow effect on the entropy generation due to the use of $\mathrm{Cu}$-water nanofluids in an open cavity where the bottom side was heated. They concluded that the average Nusselt number and entropy generation were enhanced with particle loading. Furthermore, it was found that the amount of increase in the Nusselt number and entropy generation depends on the intensity of the magnetic field (Hartmann number), and the angle at which the magnetic field is applied.

Heat transport can be controlled by installing differently shaped passive elements in open or closed cavities. In this context, conjugate heat transfer in a partially open square closed space with a vertical heat source has been simulated by Koca [13]. In this case, the closed space had an opening on the top side where the position and size of opening was changed. It was found that ventilation location has a significant influence on the heat transfer rate. Nasrin [14] concluded that obstacles could be used as effective tools to control the heat transfer in cavities where MHD flow is considered in the problem.

Hussein et al. [15] solved the three-dimensional buoyancy-induced flow and entropy generation in a trapezoidal closed space with different slopes filled with air for Rayleigh numbers in the range of $10^{3}$ and $10^{5}$. The closed space was heated from the bottom wall while the left and right sides were kept at a lower temperature compared to the bottom. They found that at low Rayleigh numbers, the slope of the closed space has no effect on the total entropy generation.

This literature review indicates that most studies on buoyancy-induced flow in open cavities have been considered as 2D dimensional problems. The main aim of this paper was to perform a 3D analysis of heat transport of nanofluids in an open cavity with a diamond shaped obstacle in the middle of a closed space.

\section{Definition of the Physical Model}

Figure 1 displays a schematic of the present problem. As shown, the left side of the closed space has a higher temperature than the right side that is considered as the opening. Other walls are assumed to be adiabatic. A diamond shaped obstacle with a side size of $\mathrm{Ld}$ and insulated walls is inserted in the middle of the closed space. The space between the closed space and the obstacle is filled with $\mathrm{Al}_{2} \mathrm{O}_{3}$ /water nanofluid. 


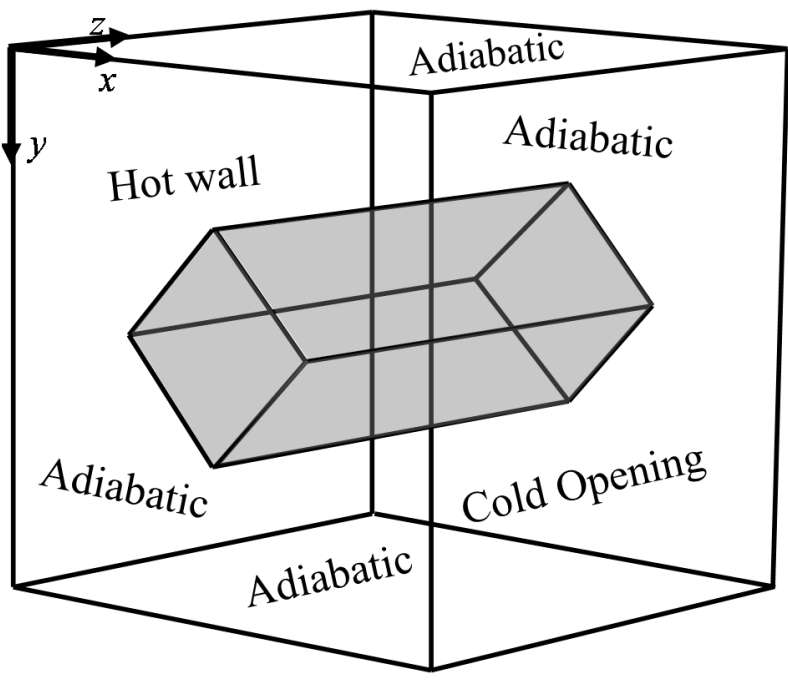

(a)

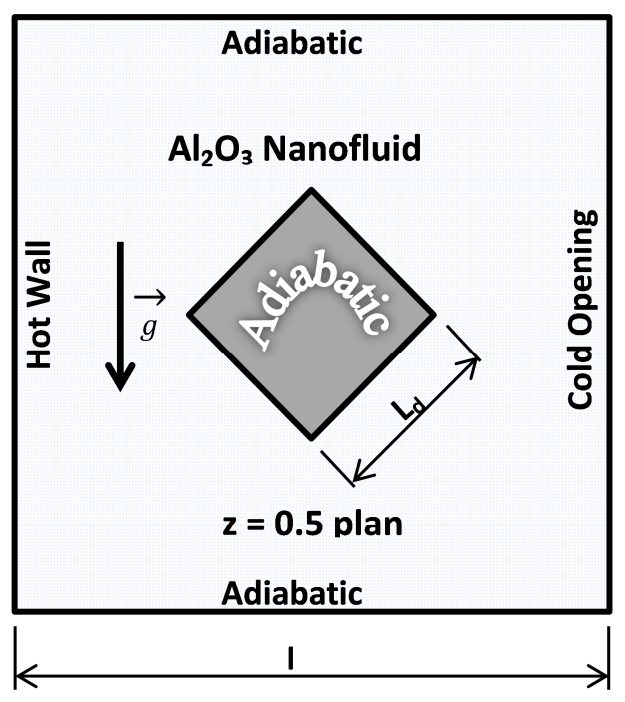

(b)

Figure 1. Physical model with boundary conditions.

The nanofluid is assumed to be incompressible and the flow is considered laminar. The base fluid and nanoparticles are assumed to be at thermal equilibrium. Table 1 presents the thermo-physical properties of the base fluid (water) and the nanoparticles.

Table 1. Thermo-physical properties of nanoparticles and base fluid.

\begin{tabular}{ccc}
\hline Properties & $\mathbf{A l}_{\mathbf{2}} \mathbf{O}_{\mathbf{3}}$ & Water \\
\hline$C_{p}\left(\mathrm{~J} \cdot \mathrm{kg}^{-1} \cdot{ }^{\circ} \mathrm{C}^{-1}\right)$ & 765 & 4179 \\
$\rho\left(\mathrm{kg} \cdot \mathrm{m}^{-3}\right)$ & 3970 & 997.1 \\
$k\left(\mathrm{~W} \cdot \mathrm{m}^{-1} \cdot{ }^{\circ} \mathrm{C}^{-1}\right)$ & 40 & 0.613 \\
$\alpha \times 10^{7}\left(\mathrm{~m}^{2} \cdot \mathrm{s}^{-1}\right)$ & 131.7 & 1.47 \\
$\beta \times 10^{-5}\left(\mathrm{~K}^{-1}\right)$ & 0.85 & 21 \\
\hline
\end{tabular}

\subsection{Governing Equations}

Equations governing the studied configuration were written using the $3 \mathrm{D}$ vorticity-vector potential formalism $(\vec{\psi}-\vec{\omega})$. This formalism allows the elimination of the pressure which is delicate to treat. Vorticity and vector potential are defined respectively by the following two relations:

$$
\overrightarrow{\omega^{\prime}}=\vec{\nabla} \times \overrightarrow{V^{\prime}}
$$

and

$$
\overrightarrow{V^{\prime}}=\vec{\nabla} \times \overrightarrow{\psi^{\prime}}
$$

Using the dimensionless variables the governing equations are written in the following form:

$$
\begin{gathered}
-\vec{\omega}=\nabla^{2} \vec{\psi} \\
\frac{\partial \vec{\omega}}{\partial t}+(\vec{V} \cdot \nabla) \vec{\omega}=(\vec{\omega} \cdot \nabla) \vec{V}+\frac{v_{n f}}{v_{f}} \operatorname{Pr} \cdot \nabla^{2} \vec{\omega}-\frac{\beta_{n f}}{\beta_{f}} \operatorname{Ra} \operatorname{Pr} \nabla \times T \vec{g} \\
\frac{\partial T}{\partial t}+\vec{V} \cdot \nabla T=\frac{\alpha_{n f}}{\alpha_{f}} \nabla^{2} T
\end{gathered}
$$


The velocity $\left(\overrightarrow{V^{\prime}}\right)$, time $\left(t^{\prime}\right)$, vector potential $\left(\overrightarrow{\psi^{\prime}}\right)$ and vorticity $\left(\overrightarrow{\omega^{\prime}}\right)$, are put respectively in the dimensionless forms by $\alpha / l, l^{2} / \alpha, \alpha$ and $l^{2} / \alpha$ and the dimensionless temperature is written as:

$$
T=\left(T^{\prime}-T_{c^{\prime}}\right) /\left(T_{h^{\prime}}-T_{c^{\prime}}\right)
$$

In these equations, the dimensionless Pr and Ra numbers are respectively defined as:

$$
\operatorname{Pr}=\frac{v}{\alpha} \text { and } \operatorname{Ra}=\frac{g \cdot \beta \cdot \Delta T \cdot l^{3}}{v \cdot \alpha}
$$

The effective density, the specific heat, the effective thermal conductivity (Maxwell-Garnetts model) and the effective dynamic viscosity (Brinkman model) of the nanofluid are given respectively as $[16,17]$ :

$$
\begin{gathered}
\rho_{n f}=(1-\varphi) \rho_{f}+\varphi \rho_{s} \\
\left(\rho C_{p}\right)_{n f}=(1-\varphi)\left(\rho C_{p}\right)_{f}+\varphi\left(\rho C_{p}\right)_{s} \\
\frac{k_{n f}}{k_{f}}=\frac{k_{s}+2 k_{f}-2 \varphi\left(k_{f}-k_{s}\right)}{k_{s}+2 k_{f}+\varphi\left(k_{f}-k_{s}\right)} \\
\mu_{n f}=\frac{\mu_{f}}{(1-\varphi)^{2.5}}
\end{gathered}
$$

\subsection{Boundary Conditions}

For the considered configuration, the boundary conditions are:

Temperature:

$$
\begin{gathered}
T=1 \text { for } x=0 \\
\frac{\partial T}{\partial n}=0 \text { on adiabatic walls } \\
T_{\text {in }}=T c \text { if } n . V<0
\end{gathered}
$$

and

$$
\left.\frac{\partial T}{\partial n}\right|_{\text {out }}=0 \text { if } n \cdot V \geqslant 0 \text { At open boundary }
$$

Vorticity:

$$
\begin{gathered}
\omega_{x}=0, \omega_{y}=-\frac{\partial V_{z}}{\partial x} \text { and } \omega_{z}=\frac{\partial V_{y}}{\partial x} \text { at } x=0 \\
\omega_{x}=\frac{\partial V_{z}}{\partial y}, \omega_{y}=0 \text { and } \omega_{z}=-\frac{\partial V_{x}}{\partial y} \text { at } y=0 \text { and } 1 \\
\omega_{x}=-\frac{\partial V_{y}}{\partial z}, \omega_{y}=\frac{\partial V_{x}}{\partial z} \text { and } \omega_{z}=0 \text { at } z=0 \text { and } 1
\end{gathered}
$$

Vector potential:

$$
\begin{gathered}
\frac{\partial \psi_{x}}{\partial x}=\psi_{y}=\psi_{z}=0 \text { at } x=0 \\
\psi_{x}=\frac{\partial \psi_{y}}{\partial y}=\psi_{z}=0 \text { at } y=0 \text { and } 1 \\
\psi_{x}=\psi_{y}=\frac{\partial \psi_{z}}{\partial z}=0 \text { at } z=0 \text { and } 1
\end{gathered}
$$

Velocity:

$$
V_{x}=V_{y}=V_{z}=0 \text { on all walls }
$$




$$
\frac{\partial V_{x}}{\partial x}=\frac{\partial V_{y}}{\partial x}=\frac{\partial V_{z}}{\partial x}=0 \text { at open boundary }
$$

The expression of the dimensional generated entropy $\left(S_{\text {gen }}^{\prime}\right)$ is presented by Equation (22):

$$
\begin{aligned}
& S_{\text {gen }}^{\prime}=\left\{\frac{k_{n f}}{T_{0}^{2}}\left[\left(\frac{\partial T^{\prime}}{\partial x^{\prime}}\right)^{2}+\left(\frac{\partial T^{\prime}}{\partial y^{\prime}}\right)^{2}+\left(\frac{\partial T^{\prime}}{\partial z^{\prime}}\right)^{2}\right]\right\}+ \\
& \frac{\mu_{n f}}{T_{0}}\left\{2\left[\left(\frac{\partial V_{x}^{\prime}}{\partial x^{\prime}}\right)^{2}+\left(\frac{\partial V_{y}^{\prime}}{\partial y^{\prime}}\right)^{2}+\left(\frac{\partial V_{z}^{\prime}}{\partial z^{\prime}}\right)^{2}\right]+\left(\frac{\partial V_{y}^{\prime}}{\partial x^{\prime}}+\frac{\partial V_{x}^{\prime}}{\partial y^{\prime}}\right)^{2}+\left(\frac{\partial V_{z}^{\prime}}{\partial y^{\prime}}+\frac{\partial V_{y}^{\prime}}{\partial z^{\prime}}\right)^{2}+\left(\frac{\partial V_{x}^{\prime}}{\partial z^{\prime}}+\frac{\partial V_{z}^{\prime}}{\partial x^{\prime}}\right)^{2}\right\}
\end{aligned}
$$

Put in its dimensionless form, the local generated entropy $\left(N_{s}\right)$ is written as:

$$
\begin{aligned}
& N_{s}=\frac{k_{n f}}{k_{f}}\left[\left(\frac{\partial T}{\partial x}\right)^{2}+\left(\frac{\partial T}{\partial y}\right)^{2}+\left(\frac{\partial T}{\partial z}\right)^{2}\right] \\
& +\varphi_{S} \frac{\mu_{n f}}{\mu_{f}}\left\{2\left[\left(\frac{\partial V_{x}}{\partial x}\right)^{2}+\left(\frac{\partial V_{y}}{\partial y}\right)^{2}+\left(\frac{\partial V_{z}}{\partial z}\right)^{2}\right]+\left[\left(\frac{\partial V_{y}}{\partial x}+\frac{\partial V_{x}}{\partial y}\right)^{2}+\left(\frac{\partial V_{z}}{\partial y}+\frac{\partial V_{y}}{\partial z}\right)^{2}+\left(\frac{\partial V_{x}}{\partial z}+\frac{\partial V_{z}}{\partial x}\right)^{2}\right]\right\}
\end{aligned}
$$

In this equation another dimensionless parameter appears, this number is the irreversibility coefficient defined by:

$$
\varphi_{S}=\left(\frac{\alpha}{l \Delta T}\right)^{2} T_{0}
$$

The local generated entropy is the sum of two types of entropies; the first one is due to temperature gradients $\left(N_{s-t h}\right)$ and the second is due to viscous effects $\left(N_{s-f r}\right)$.

The total generated entropy $\left(S_{t o t}\right)$ is given by:

$$
S_{t o t}=\int_{v} N_{s} d v=\int_{v}\left(N_{s-t h}+N_{s-f r}\right) d v=S_{t h}+S_{f r}
$$

The Bejan number $(B e)$ is the ratio of heat transfer irreversibility to the total irreversibility due to the heat transfer and the fluid friction as:

$$
B e=\frac{S_{t h}}{S_{t h}+S_{f r}}
$$

The local Nusselt number $(\mathrm{Nu})$ is defined as follows:

$$
N u=\left.\left(\frac{k_{n f}}{k_{f}}\right) \frac{\partial T}{\partial x}\right|_{x=0,1}
$$

The average Nusselt number on the hot wall $\left(N u_{a v}\right)$, is expressed by:

$$
N u_{a v}=\int_{0}^{1} \int_{0}^{1} N u \cdot d y \cdot d z
$$

The FORTRAN language was used to write the numerical program allowing to solve the mathematical model described above. Governing Equations (2)-(4) and (23) were discretized using the control volume method based on the central-difference scheme and solved using the successive relaxation iteration scheme. Although grids are uniform in all directions, additional nodes are added on boundaries. For all numerical tests, the time step and spatial mesh are fixed respectively at $\left(10^{-4}\right)$ and $\left(81^{3}\right)$ and the convergence criterion for each step of time is chosen as:

$$
\sum_{i}^{1,2,3} \frac{\max \left|\psi_{i}^{n}-\psi_{i}^{n-1}\right|}{\max \left|\psi_{i}^{n}\right|}+\max \left|T_{i}^{n}-T_{i}^{n-1}\right| \leqslant 10^{-5}
$$




\section{Validation of the Code and Grid Dimension}

For 3D analysis, the findings of Wakashima and Saitoh [18] and Fusegi et al. [19] on buoyancyinduced flow are validated with $\mathrm{Pr}=0.71$ and shown in Table 2 . The present results are in excellent agreement with the previously reported results. After a grid sensivity test, the $81 \times 81 \times 81$ grid distribution with additional nodes in boundaries was retained. For nanofluids buoyancy-induced flow, the code was validated by comparing with the studies of Öztop and Abu-Nada [20] (Figure 2) and of Jahanshahi et al. [21] (Figure 3). It can be said from this comparison that there is good agreement.

Table 2. Comparison of present results with the 3D results of (Wakashima and Saitho [18]) and (Fusegi et al. [19]) for differentially heated cubic closed space and $\operatorname{Pr}=0.71$.

\begin{tabular}{ccccccc}
\hline $\mathbf{R a}$ & Authors & $\psi_{z}$ (Center) & $\omega_{z}$ (Center) & $V_{x \max }(\mathbf{y})$ & $V_{y \max }(\mathbf{x})$ & $N u_{a v}$ \\
\hline $10^{4}$ & Present work & 0.05528 & 1.1063 & $0.199(0.826)$ & $0.221(0.112)$ & 2.062 \\
& Wakashima and Saitho [18] & 0.05492 & 1.1018 & $0.198(0.825)$ & $0.222(0.117)$ & 2.062 \\
& Fusegi et al. [19] & - & - & $0.201(0.817)$ & $0.225(0.117)$ & 2.1 \\
\hline \multirow{2}{*}{$10^{5}$} & Present work & 0.034 & 0.262 & $0.143(0.847)$ & $0.245(0.064)$ & 4.378 \\
& Wakashima and Saitoh [18] & 0.03403 & 0.2573 & $0.147(0.85)$ & $0.246(0.068)$ & 4.366 \\
& Fusegi et al. [19] & - & - & $0.147(0.855)$ & $0.247(0.065)$ & 4.361 \\
\hline \multirow{2}{*}{$10^{6}$} & Present work & 0.01972 & 0.1284 & $0.0832(0.847)$ & $0.254(0.032)$ & 8.618 \\
& Wakashima and Saitho [18] & 0.01976 & 0.1366 & $0.0811(0.86)$ & $0.2583(0.032)$ & 8.6097 \\
& Fusegi et al. [19] & - & - & $0.0841(0.856)$ & $0.259(0.033)$ & 8.77 \\
\hline
\end{tabular}

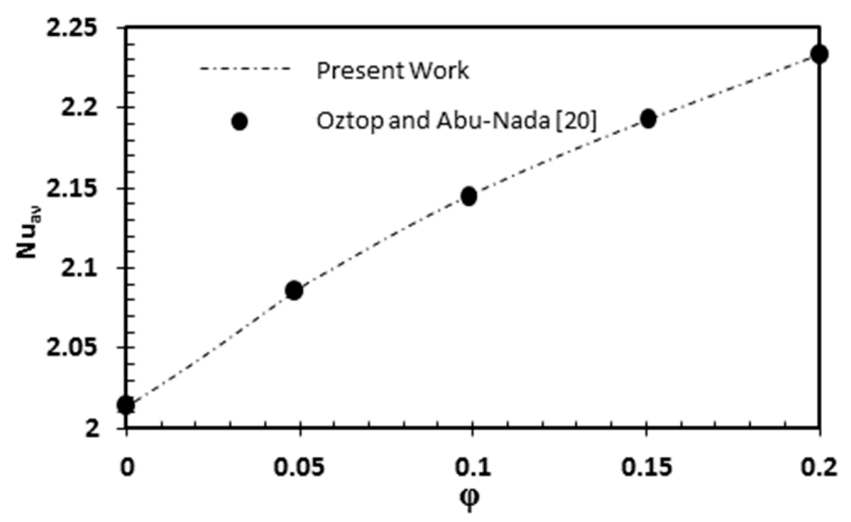

Figure 2. Nusselt number versus $\varphi$ for $\mathrm{Ra}=10^{4}$; comparison with results of Öztop and Abu-Nada [20].

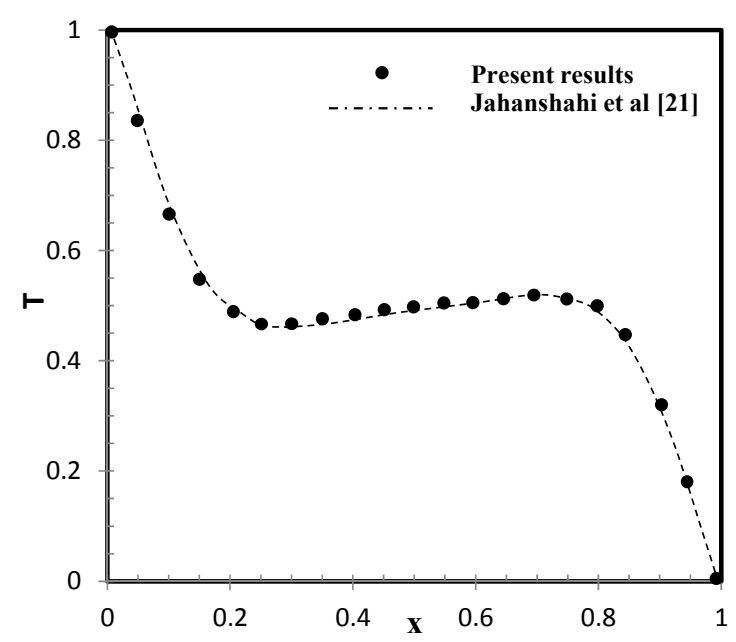

Figure 3. Comparison of the temperature on axial midline between the present results (cubic closed space; $z=0.5$ plan) and results of Jahanshahi et al. [21] $\left(\operatorname{Pr}=6.2, \varphi=0.1\right.$ and $\left.\operatorname{Ra}=6.2 \times 10^{4}\right)$. 


\section{Results and Discussion}

A computational work has been done to solve the equations of buoyancy-induced flow in a 3D open cavity with a diamond shaped obstacle. The working fluid is chosen as a nanofluid and entropy generation is also analyzed for different governing parameters such as nanoparticle volume fraction, Ra number and length of the diamond obstacle.

Streamlines and velocity vector projection at $z=0.5$ plan for different Ra numbers and nanoparticle fractions are presented in Figures 4 and 5, respectively, at $\mathrm{Ld}=0.3$. The flow enters the closed space from the bottom side and goes to the top side by surrounding the partition. Also, a small part of the fluid comes into the closed space and impinges on the inserted body and goes back. It shows small differences between nanofluid and pure fluid. Vena contracta shaped flow is formed around the inserted body. With increasing flow velocity and Ra number, a circulation cell is formed on the corner of the inserted body. This circulation cell becomes bigger with nanoparticle addition. Its dimension also increases with increasing Ra number.
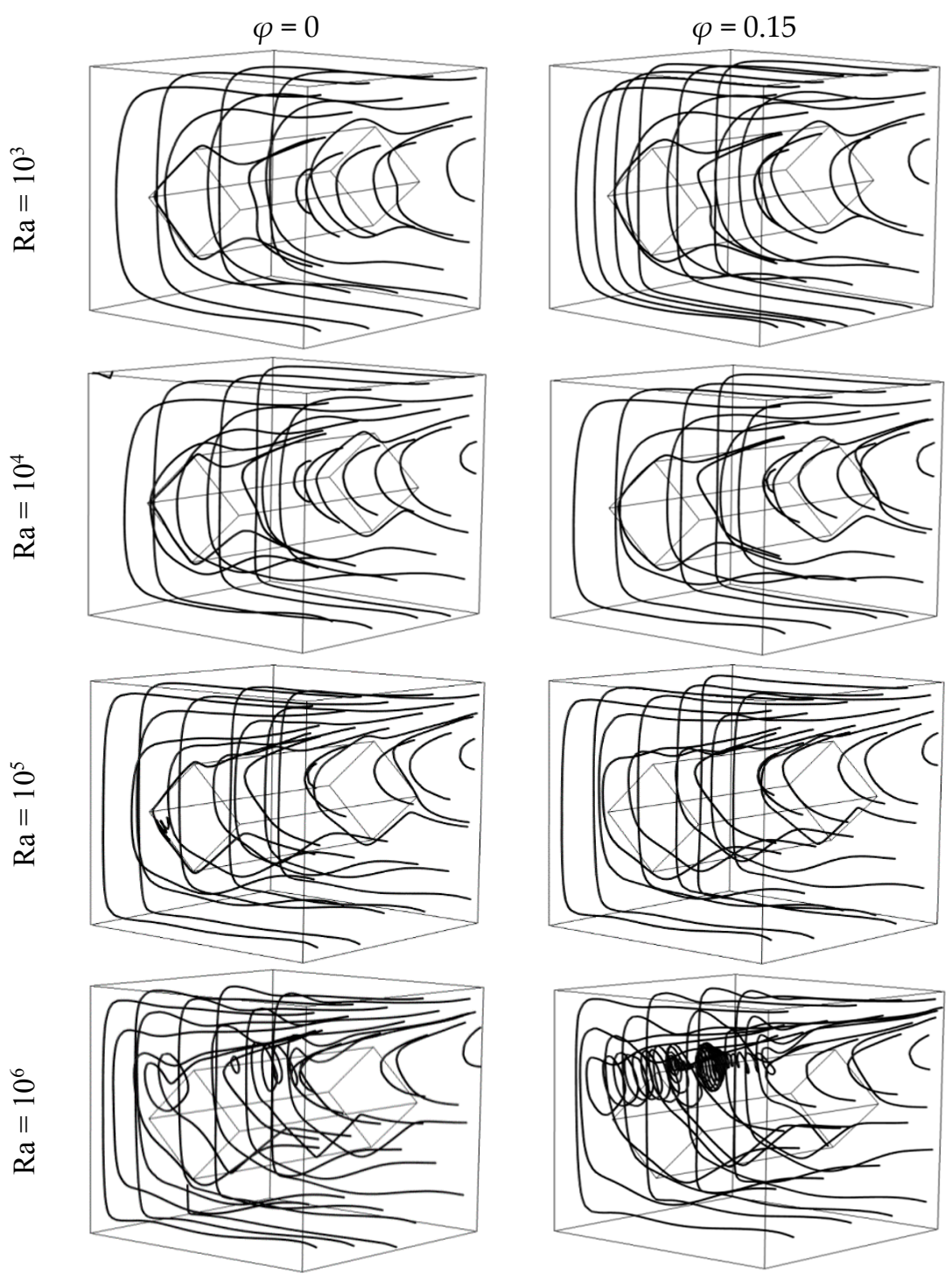

Figure 4. Streamlines for $\operatorname{Ld}=0.3$ and different $\operatorname{Ra} ;($ Left $) \varphi=0$; and (Right) $\varphi=0.15$. 

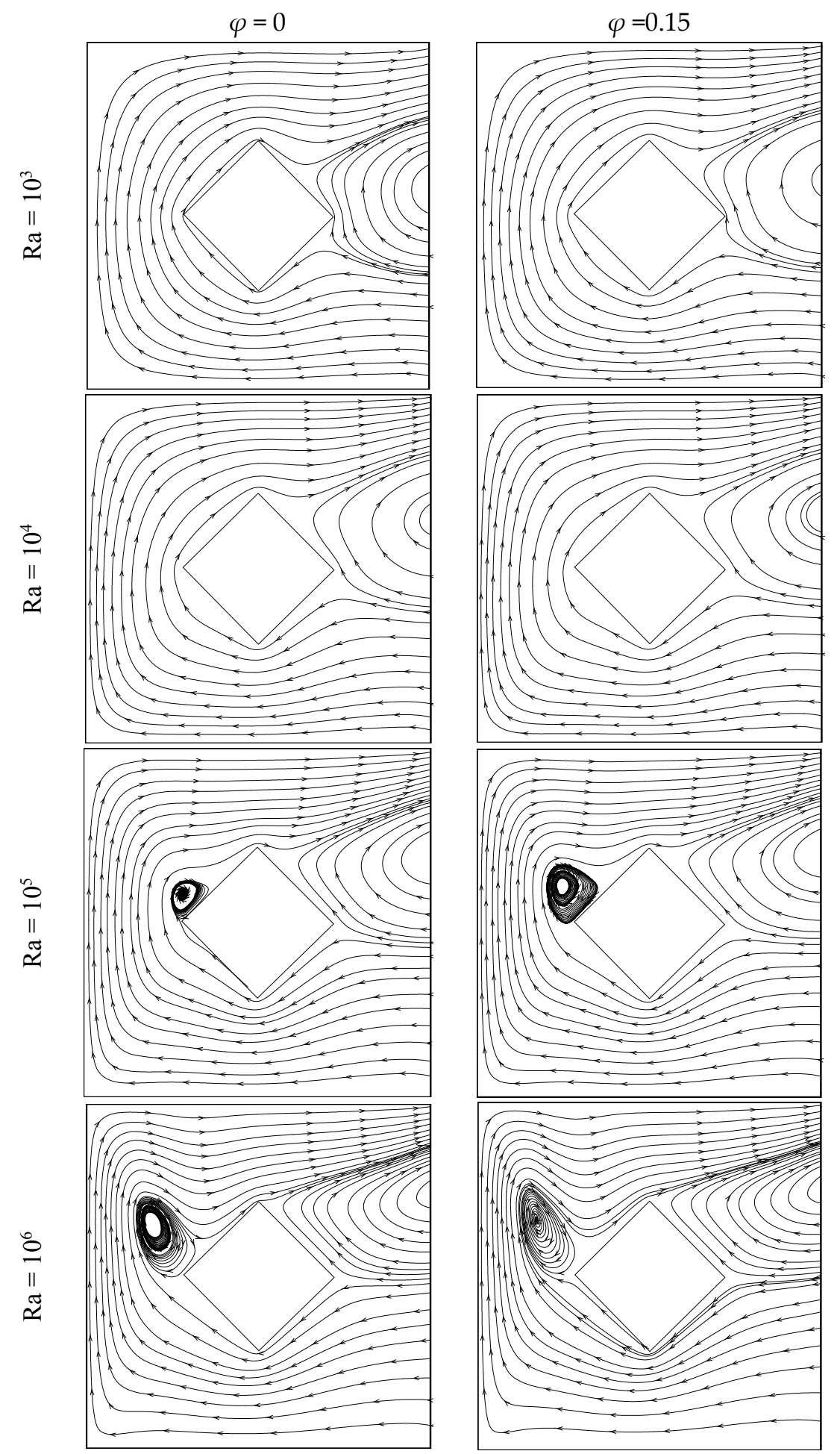

Figure 5. Velocity vector projection at $z=0.5$ plan for $\operatorname{Ld}=0.3$ and different $\operatorname{Ra}$; (Left) $\varphi=0$; and (Right) $\varphi=0.15$.

Figure 6, presents the iso-surfaces of temperature for $\mathrm{Ld}=0.3$ at different Ra numbers for both nanofluid and water. For higher values of Ra number, the thermal boundary layer becomes thinner. Thus, insertion of the body becomes more effective for the lower values of Ra number. It is noticed that the inserted body has adiabatic boundary conditions. Thus, heat is captured under the left bottom side of the partition. 


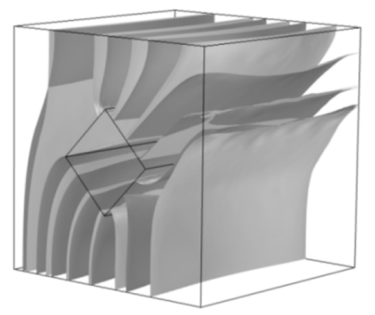

$\mathrm{Ra}=10^{3}$

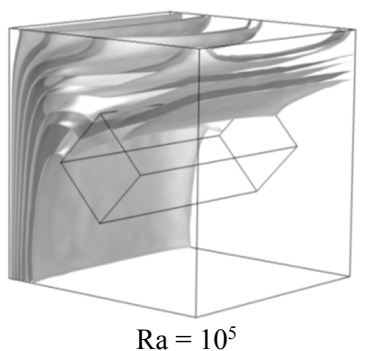

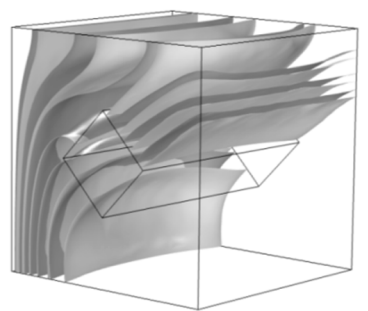

$\mathrm{Ra}=10^{4}$

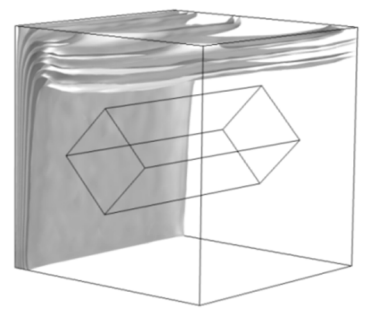

$\mathrm{Ra}=10^{6}$

Figure 6. Iso-surfaces of temperature for $\operatorname{Ld}=0.3$ and different $\operatorname{Ra}$; Dark $(\varphi=0.15)$ clear $(\varphi=0)$.

Figure 7 illustrates the isotherms for different Ra numbers and nanoparticle volume fraction at $z=0.5$. As seen from the figure, distances among isotherms are almost same due to the domination of the conduction mode of heat transfer at low Ra numbers. Thus, isotherms are distributed diagonally due to the inserted insulated material. The effects of the inserted body become less due to thinner thermal boundary layer at higher Ra number. Local thermal entropy generation is displayed for different Ra number. In Figure 8, gray lines show values for pure fluid and black ones are given for nanofluids. $S_{\text {th }}$ value becomes effective at the corners of the inserted body due to increases in kinetic energy. It is also cumulated mostly at the bottom side of the left vertical wall due to heat transport way. The inserted body behaves as an insulated wall. When values of Ra number increase the thermal boundary layer becomes thinner and the inserted body becomes insignificant on $S_{\text {th }}$ value. Figure 9 illustrates the entropy generation due to fluid friction. Again, the edge of the inserted body becomes significant in entropy generation. Also, boundaries are effective for entropy generation. Especially, the top outlet edge becomes effective in entropy generation due to fluid friction, because friction is increased at that part of the flow.

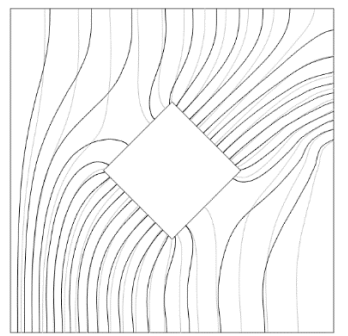

$\mathrm{Ra}=10^{3}$

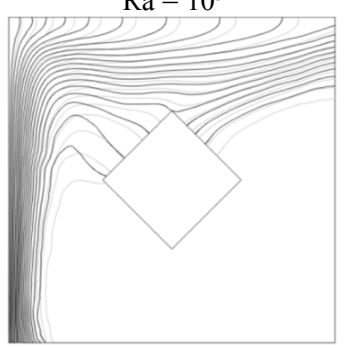

$\mathrm{Ra}=10^{5}$

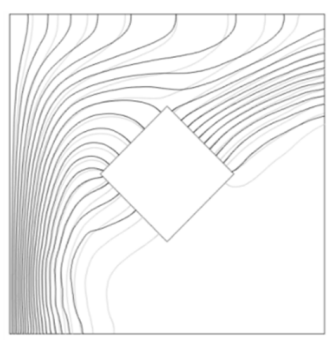

$\mathrm{Ra}=10^{4}$

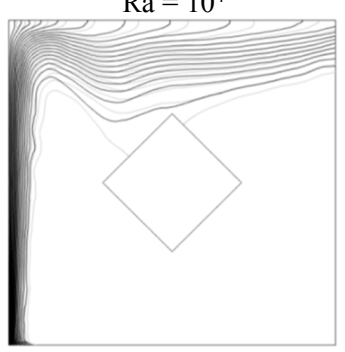

$\mathrm{Ra}=10^{6}$

Figure 7. Isotherms at $z=0.5$ plan for $\operatorname{Ld}=0.3$ and different $\operatorname{Ra}$; (gray) $\varphi=0$; (black) $\varphi=0.15$. 


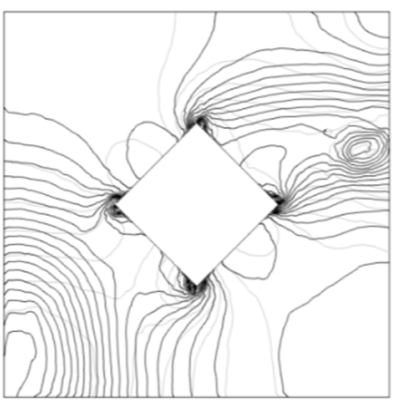

$\mathrm{Ra}=10^{3}$

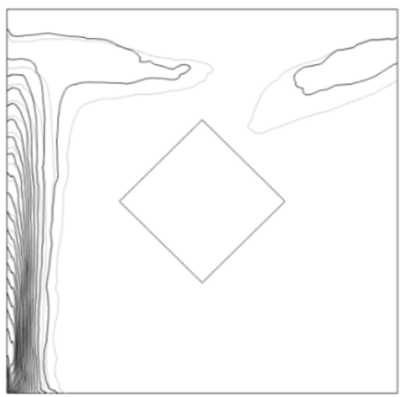

$\mathrm{Ra}=10^{5}$

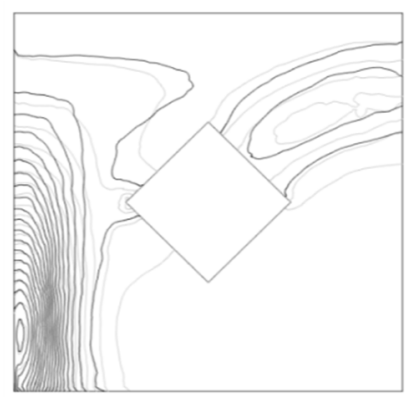

$\mathrm{Ra}=10^{4}$

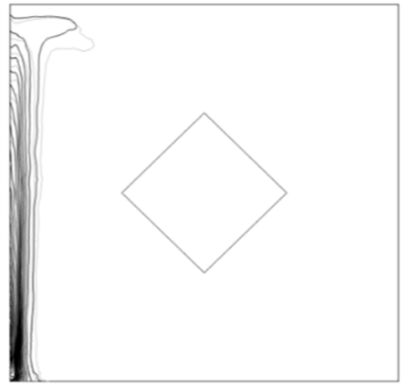

$\mathrm{Ra}=10^{6}$

Figure 8. Local thermal entropy generation $\left(S_{t h}\right)$ at $z=0.5$ plan for $\mathrm{Ld}=0.3$ and different $\mathrm{Ra}$; (gray) $\varphi=0$; (black) $\varphi=0.15$.
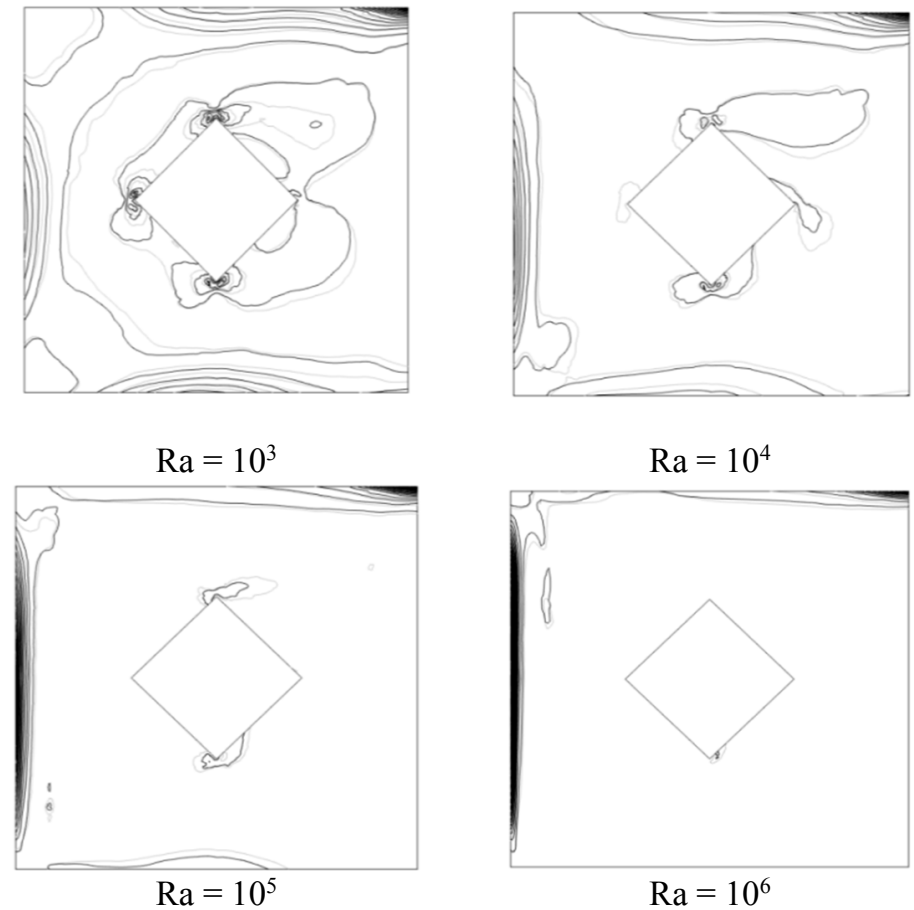

Figure 9. Local entropy generation due to friction $\left(\mathrm{S}_{\mathrm{fr}}\right)$ at $z=0.5$ plan for $\mathrm{Ld}=0.3$ and different $\mathrm{Ra}$; (gray) $\varphi=0$; (black) $\varphi=0.15$.

Total entropy generation is presented in Figure 10 for the same parameters as Figures 8 and 9. Figure 11 shows the variation of average Nusselt number along the hot wall as a function of nanoparticle volume fraction at different Ra numbers. For $\mathrm{Ra}=10^{3}$ and $10^{4}$, heat transport becomes constant with volume fraction, due to the domination of conduction mode. For higher Ra, heat transfer increase by increasing the nanoparticle volume fraction. 


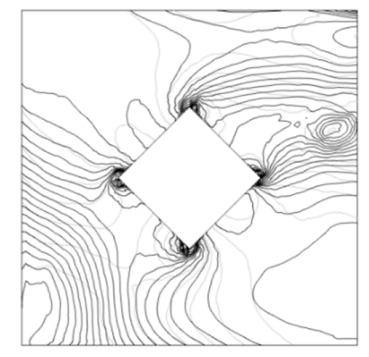

$\mathrm{Ra}=10^{3}$

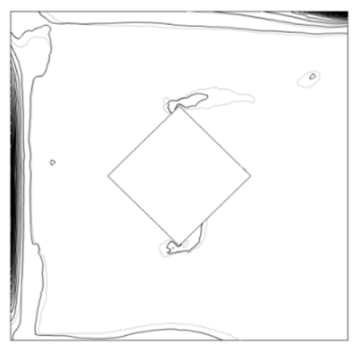

$\mathrm{Ra}=10^{5}$

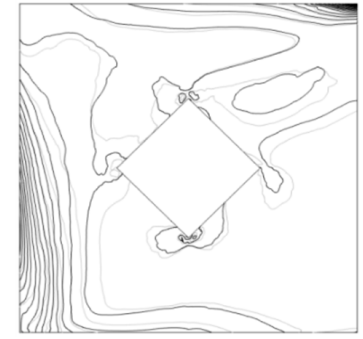

$\mathrm{Ra}=10^{4}$

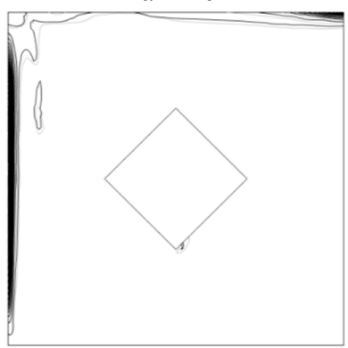

$\mathrm{Ra}=10^{6}$

Figure 10. Local total entropy generation $\left(S_{\text {tot }}\right)$ at $z=0.5$ plan for $\operatorname{Ld}=0.3$ and different $\operatorname{Ra}$; (gray) $\varphi=0$; (black) $\varphi=0.15$.

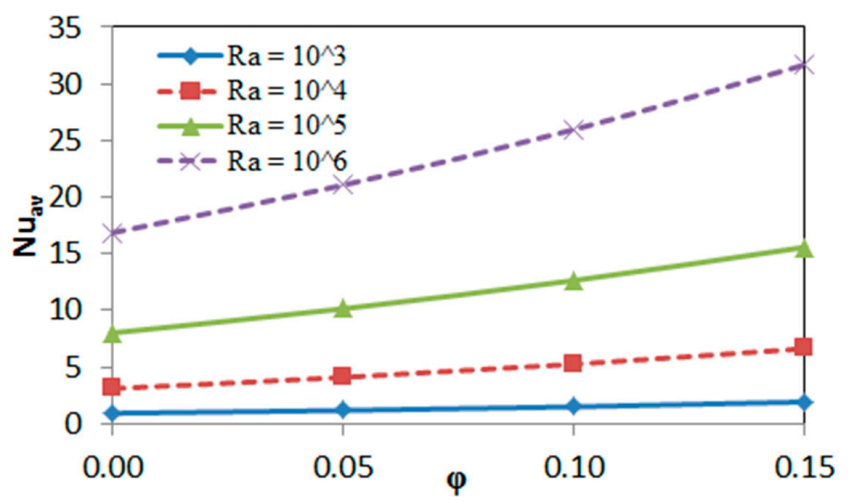

Figure 11. Average Nusselt number at hot wall as function of $\varphi$ for $\operatorname{Ld}=0.3$ and different $\operatorname{Ra}$.

Geometric effects of the inserted body are presented in Figure 12 for the highest value of Ra number. As seen from the figure, the dimension of the partition is the main effective parameter in the flow structure inside the closed space. In any case, a circulation cell occurs due to flow separation of the corner of the partition. Also, another mini-circulation cell is formed under this circulation cell. For the biggest partition, the flow is obstructed from the outside. Nanoparticle addition has less effect on flow structure.

In the same manner, isotherms are given in Figure 13 for different nanoparticle volume fraction at $z=0.5$ for $\mathrm{Ra}=10^{6}$. The small partition size becomes insignificant in the temperature distribution. However, temperature distribution is affected by the partition and the high temperature penetrates into the cavity.

Average Nusselt number is illustrated for the considered parameters in Figure 14. As seen from the figure, the general trend with geometrical parameter is a small decrease. However, higher heat transfer is obtained with the addition of nanoparticles into the base fluid. Variation of $S_{\text {th }}$ value with geometrical parameter is plotted in Figure 15 at different Ra numbers. As given in the figure, entropy generation becomes almost constant with geometrical parameters for lower Ra numbers. However, it is increased with the increase of geometrical parameter at higher values of the Ra number due to increase in heat transfer. Entropy generation due to friction as a function of geometrical parameter for 
different nanoparticle volume fraction is shown in Figure 16(a) for lower Ra numbers and Figure 16b for higher Ra numbers. It is an interesting result that heat transfer is decreased for $\mathrm{Ld}>0.3$ due to the obstruction effect of the inserted body. Entropy generation due to fluid friction becomes constant for different geometrical parameters at $\mathrm{Ra}=10^{5}$ for both nanofluid and pure fluid. It is increased with geometrical parameter for $\mathrm{Ra}=10^{6}$ and higher heat transfer occurs for nanofluids.
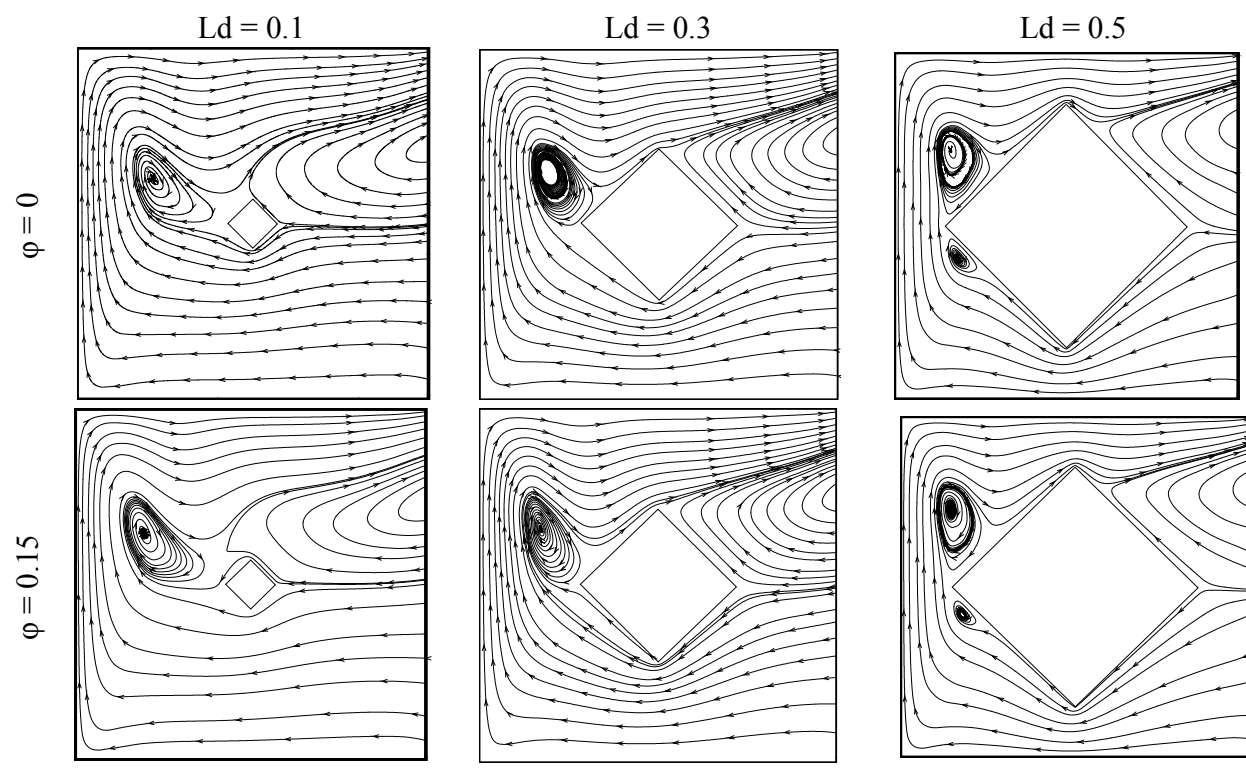

Figure 12. Velocity vector projection at $z=0.5$ plan for $\mathrm{Ra}=10^{6}$ and different $\mathrm{Ld}=0.3$.
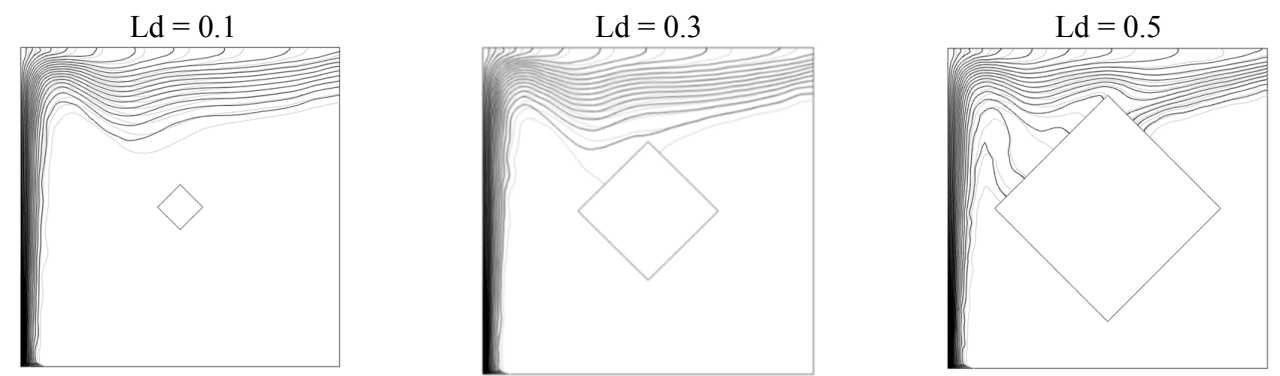

Figure 13. Isotherms at $z=0.5$ plan for $\operatorname{Ra}=10^{6}$ and different $\operatorname{Ld}$ (gray) $\varphi=0$; (black) $\varphi=0.15$.

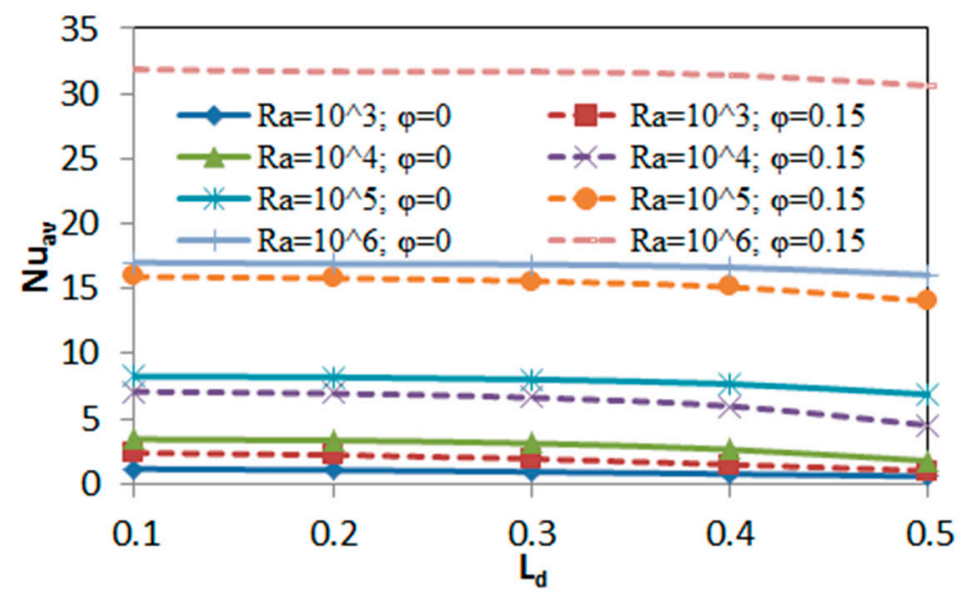

Figure 14. Average Nusselt number at hot wall for $\varphi=0$ and $\varphi=0.15$ and different Ra. 


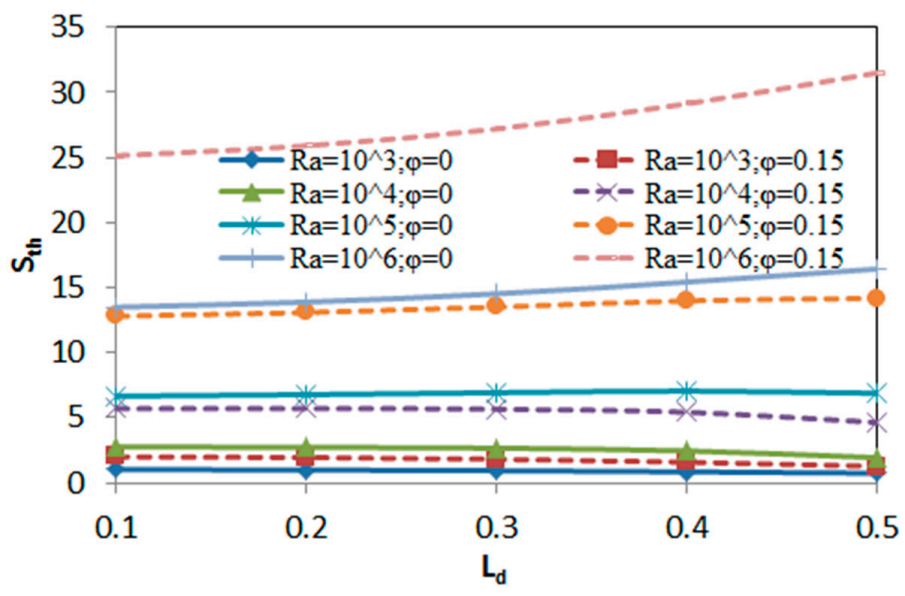

Figure 15. Thermal entropy generation as function of $\operatorname{Ld}$ for $\varphi=0$ and $\varphi=0.15$ and different Ra.

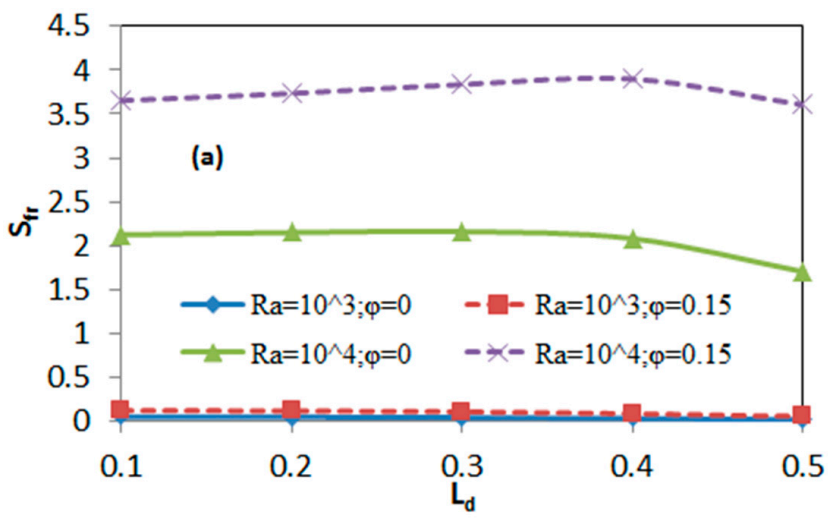

(a)

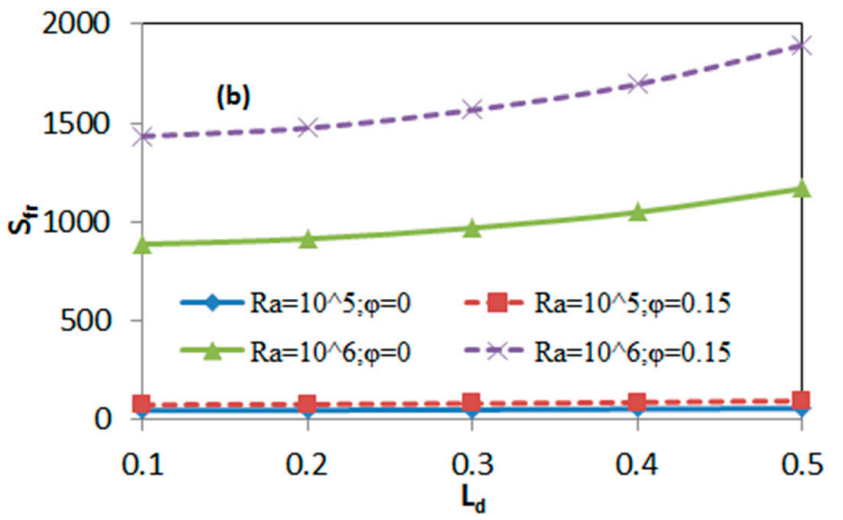

(b)

Figure 16. Entropy generation due to friction as a function of $\operatorname{Ld}$ for $\varphi=0$ and $\varphi=0.15$ and different $\mathrm{Ra}$; (a) $\mathrm{Ra}=10^{3}$ and $10^{4}$; (b) $\mathrm{Ra}=10^{5}$ and $10^{6}$.

Figure 17 illustrates the total entropy generation for the chosen parameters. Total entropy generation becomes almost constant for $\mathrm{Ra}=10^{5}$ with $\mathrm{Ld}$ values and higher values are formed for nanofluids. However, entropy generation is increased almost linearly with $\mathrm{Ld}$ values for $\mathrm{Ra}=10^{6}$. On the contrary, entropy generation decreases with Ld values due to obstruction of the inserted body. Finally, Figure 18 presents the variation of Bejan number with Ld values at different Ra number and nanoparticle volume fraction. This value becomes almost constant for the highest value of Ra number for all values of geometrical parameters. On the contrary, Bejan number is decreased with increasing 
the geometrical parameter but in any cases, higher values are formed for the case of nanofluids. This decreasing trend is also valid for $\mathrm{Ra}=10^{4}$.

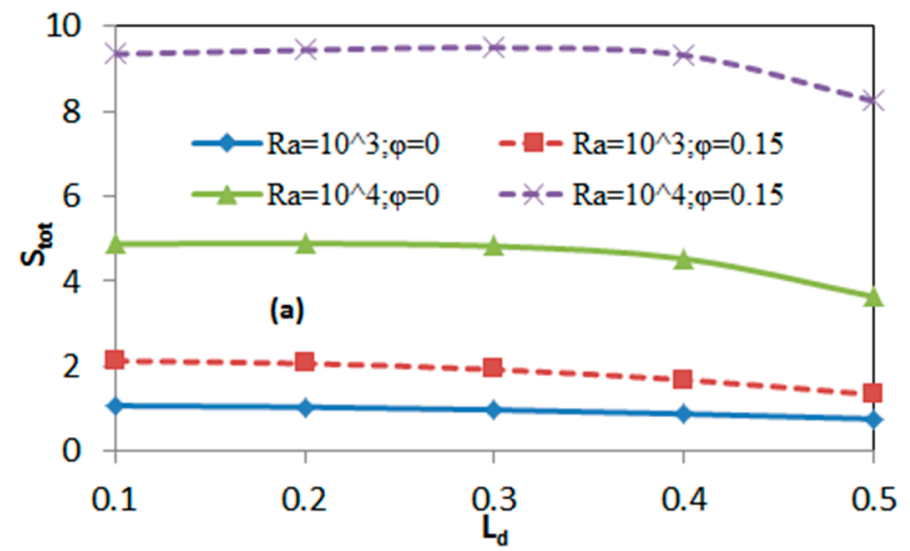

(a)

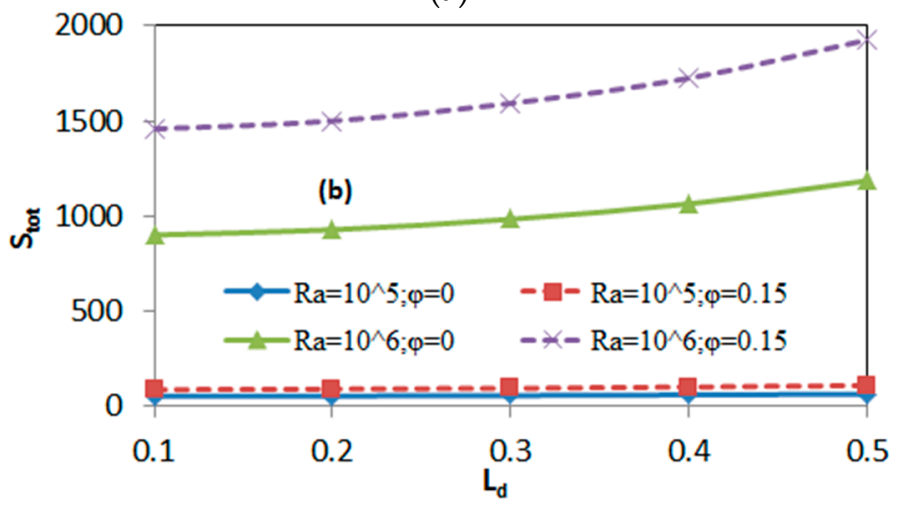

(b)

Figure 17. Total entropy generation as function of $\operatorname{Ld}$ for $\varphi=0$ and $\varphi=0.15$ and different $\operatorname{Ra}$; (a) $\operatorname{Ra}=10^{3}$ and $10^{4} ;(\mathbf{b}) \mathrm{Ra}=10^{5}$ and $10^{6}$.

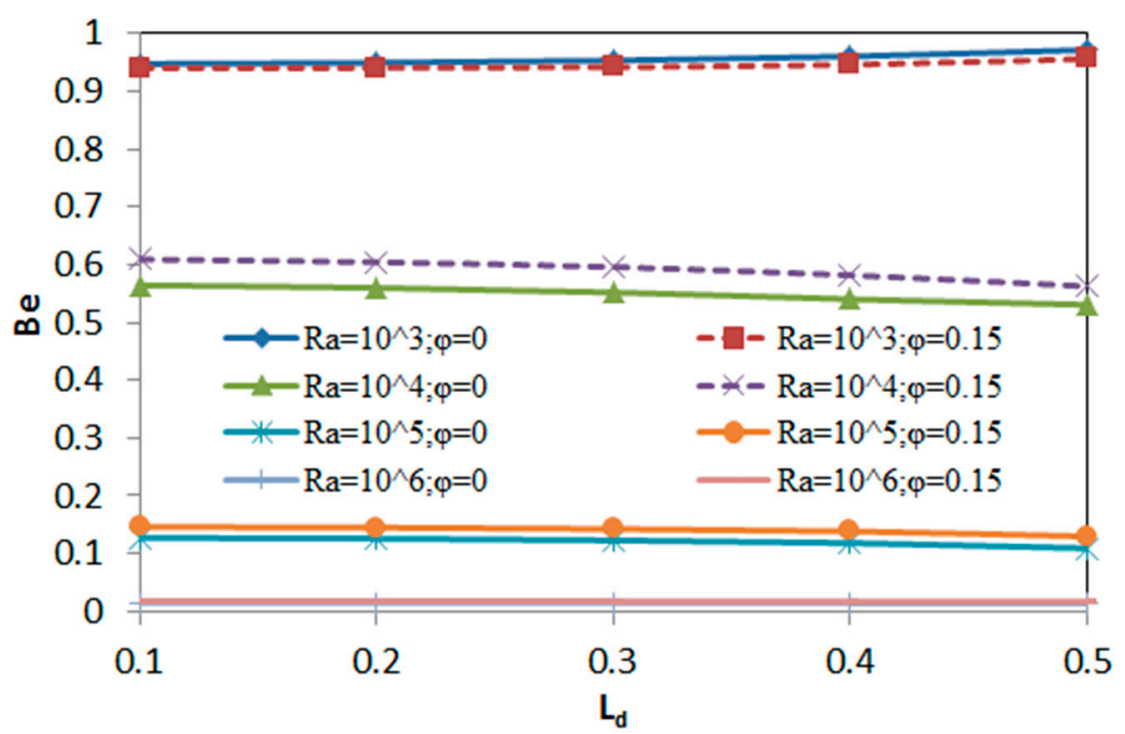

Figure 18. Bejan number as function of $\operatorname{Ld}$ for $\varphi=0$ and $\varphi=0.15$ and different Ra. 


\section{Conclusions}

A computational study has been done in this work to obtain the heat transfer, fluid flow and entropy generation for different parameters such as nanofluids, geometrical parameter and Ra numbers. An inserted body can be used to control heat transfer, fluid flow and energy efficiency inside the closed space. Thus, Bejan number becomes almost fixed for the highest value of Ra number and it decreases with increasing geometrical value, but it decreases for lower values of Ra numbers. In any case both heat transfer and entropy generation augment with addition of nanoparticle. The increase of geometrical parameter enhances the total entropy generation due to the enhancement of entropy generation with heat transfer. Circulation cells inside the enclosure are a function of the geometrical parameters of the inserted body.

Author Contributions: In this paper, Hakan F. Öztop, Lioua Kolsi and Omid Mahian Conceived and designed the numerical experiments. Lioua Kolsi and Walid Aich performed the experiments. Nidal Abu-Hamdeh, Mohamed Naceur Borjini and Habib Ben Aissia analyzed the data. Hakan F. Öztop, Omid Mahian and Lioua Kolsi wrote the paper.

Conflicts of Interest: The authors declare that there is no conflict of interest.

\section{Nomenclature}

Be

$C_{p}$

G

$k$

$l$

Ld

N

$N_{S}$

$\mathrm{Nu}$

$\operatorname{Pr}$

Ra

SIgen

$t$

$T$

$T_{c}^{\prime}$

$T_{h}^{\prime}$

$T_{o}$

$\vec{V}$

$x, y, z$

Bejan number

Specific heat at constant pressure $(\mathrm{J} / \mathrm{kg} \cdot \mathrm{K})$

Gravitational acceleration $\left(\mathrm{m} / \mathrm{s}^{2}\right)$

Thermal conductivity $(\mathrm{W} / \mathrm{m} \cdot \mathrm{K})$

Enclosure width and height $(\mathrm{m})$

Diamond width

Unit vector normal to the wall

Dimensionless local generated entropy

Local Nusselt number

Prandtl number

Rayleigh number

Generated entropy $(\mathrm{kJ} / \mathrm{kg} \cdot \mathrm{K})$

Dimensionless time $\left(t^{\prime} \cdot \alpha / l^{2}\right)$

Dimensionless temperature $\left[\left(T^{\prime}-T_{c}^{\prime}\right) /\left(T_{h}^{\prime}-T_{c}^{\prime}\right)\right]$

Cold temperature $(\mathrm{K})$

Hot temperature $(\mathrm{K})$

Bulk temperature $\left[T_{o}=\left(T^{\prime}{ }_{c}+T^{\prime}{ }_{h}\right) / 2\right](\mathrm{K})$

Dimensionless velocity vector $\left(\vec{V}^{\prime} \cdot l / \alpha\right)$

Dimensionless Cartesian coordinates $\left(x^{\prime} / l, y^{\prime} / l, z^{\prime} / l\right)$

\section{Greek symbols}

$\begin{array}{ll}\alpha & \text { Thermal diffusivity }\left(\mathrm{m}^{2} / \mathrm{s}\right) \\ \beta & \text { Thermal expansion coefficient }(1 / \mathrm{K}) \\ \rho & \text { Density }\left(\mathrm{kg} / \mathrm{m}^{3}\right) \\ \mu & \text { Dynamic viscosity }(\mathrm{kg} / \mathrm{m} \cdot \mathrm{s}) \\ v & \text { Kinematic viscosity }\left(\mathrm{m}^{2} / \mathrm{s}\right) \\ \varphi & \text { Nanoparticles volume fraction } \\ \varphi_{S} & \text { Irreversibility coefficient } \\ \vec{\psi} & \left.\text { Dimensionless vector potential } \overrightarrow{\psi^{\prime}} / \alpha\right) \\ \vec{\omega} & \text { Dimensionless vorticity }\left(\overrightarrow{\omega^{\prime}} \cdot \alpha / l^{2}\right) \\ \Delta T & \text { Dimensionless temperature difference }\end{array}$




\section{Subscripts}

$\begin{array}{ll}A v & \text { Average } \\ x, y, z & \text { Cartesian coordinates } \\ f r & \text { Friction } \\ f & \text { Fluid } \\ n f & \text { Nanofluid } \\ s & \text { Solid } \\ t h & \text { Thermal } \\ \text { tot } & \text { Total }\end{array}$

\section{Superscript}

Dimensional variable

\section{References}

1. Bilgen, E.; Öztop, H. Natural convection heat transfer in partially open inclined square cavities. Int. J. Heat Mass Transf. 2005, 48, 1470-1479. [CrossRef]

2. Prakash, M.; Kedare, S.B.; Nayak, J.K. Numerical study of natural convection loss from open cavities. Int. J. Ther. Sci. 2012, 51, 23-30. [CrossRef]

3. Zamora, B.; Kaiser, A.S. 3D effects in numerical simulations of convective flows in cubical open cavities. Int. J. Ther. Sci. 2014, 77, 172-185. [CrossRef]

4. Jafari, M.; Farhadi, M.; Akbarzade, S.; Ebrahimi, M. Lattice Boltzmann simulation of natural convection heat transfer of SWCNT-nanofluid in an open enclosure. Ain. Shams Eng. J. 2015, 6, 913-927. [CrossRef]

5. Sheremet, M.A.; Pop, I.; Shenoy, A. Unsteady free convection in a porous open wavy cavity filled with a nanofluid using Buongiorno's mathematical model. Int. Commun. Heat Mass Transf. 2015, 67, 66-72. [CrossRef]

6. Kefayati, G.H.R. FDLBM simulation of entropy generation due to natural convection in an enclosure filled with non-Newtonian nanofluid. Powder Technol. 2015, 273, 176-190. [CrossRef]

7. Kefayati, G.H.R. Effect of a magnetic field on natural convection in an open cavity subjugated to water/alumina nanofluid using Lattice Boltzmann method. Int. Commun. Heat Mass Transf. 2013, 40, 67-77. [CrossRef]

8. Mejri, I.; Mahmoudi, A. MHD natural convection in a nanofluid-filled open enclosure with a sinusoidal boundary condition. Chem. Eng. Res. Design 2015, 98, 1-16. [CrossRef]

9. Öztop, H.F.; Al-Salem, K. A review on entropy generation in natural and mixed convection heat transfer for energy systems. Renew. Sustain. Energy Rev. 2012, 16, 911-920. [CrossRef]

10. Öztop, H.F.; Kolsi, L.; Al-Salem, K. Numerical study of three-dimensional combined buoyancy and thermocapillary convection and evaluation of entropy generation. Int. J. Numer. Methods Heat Fluid Flow 2014, 24, 148-168. [CrossRef]

11. Famouri, M.; Hooman, K. Entropy generation for natural convection by heated partitions in a cavity. Int. Commun. Heat Mass Transf. 2008, 35, 492-502. [CrossRef]

12. Mehrez, Z.; El Gafsi, A.; Belghith, A.; Le Quéré, P. MHD effects on heat transfer and entropy generation of nanofluid flow in an open cavity. J. Magn. Magn. Mater. 2015, 374, 214-224. [CrossRef]

13. Koca, A. Numerical analysis of conjugate heat transfer in a partially open square cavity with a vertical heat source. Int. Commun. Heat Mass Transf. 2008, 35, 1385-1395. [CrossRef]

14. Nasrin, R. Finite element simulation of hydromagnetic convective flow in an obstructed cavity. Int. Commun. Heat Mass Transf. 2011, 38, 625-632. [CrossRef]

15. Hussein, A.K.; Kolsi, L.; Chand, R.; Sivasankaran, S.; Nikbakhti, R.; Li, D.; Borjini, M.N.; Habib, B.A. Three-dimensional unsteady natural convection and entropy generation in an inclined cubical trapezoidal cavity with an isothermal bottom wall. Alexandria Eng. J. 2016, 55, 203-214. [CrossRef]

16. Mahian, O.; Kianifar, A.; Kleinstreuer, C.; Moh'd, A.A.; Pop, I.; Sahin, A.Z.; Wongwises, S. A review of entropy generation in nanofluid flow. Int. J. Heat Mass Transf. 2013, 65, 514-532. [CrossRef] 
17. Costa, V.A.F.; Oliveira, M.S.A.; Sousa, A.C.M. Control of laminar natural convection in differentially heated square enclosures using solid inserts at the corners. Int. J. Heat Mass Transf. 2013, 46, 3529-3537. [CrossRef]

18. Wakashima, S.; Saitoh, T.S. Benchmark solutions for natural convection in a cubic cavity using the high-order time-space method. Int. J. Heat Mass Transf. 2004, 47, 853-864. [CrossRef]

19. Fusegi, T.; Hyun, J.M.; Kuwahara, K.; Farouk, B. A numerical study of three-dimensional natural convection in a differentially heated cubical enclosure. Int. J. Heat Mass Transf. 1991, 34, 1543-1557. [CrossRef]

20. Öztop, H.F.; Abu-Nada, E. Numerical study of natural convection in partially heated rectangular enclosures filled with nanofluids. Int. J. Heat Fluid Flow 2008, 29, 1326-1336. [CrossRef]

21. Jahanshahi, M.; Hosseinizadeh, S.F.; Alipanah, M.; Dehghani, A.; Vakilinejad, G.R. Numerical simulation of free convection based on experimental measured conductivity in a square cavity using Water $/ \mathrm{SiO}_{2}$ nanofluid. Int. Commun. Heat Mass Transf. 2010, 37, 687-694. [CrossRef]

(C) 2016 by the authors; licensee MDPI, Basel, Switzerland. This article is an open access article distributed under the terms and conditions of the Creative Commons Attribution (CC-BY) license (http://creativecommons.org/licenses/by/4.0/). 